\title{
Steeds complexere zorg vraagt om teamwerk
}

\author{
Citation for published version (APA):
}

van Dongen, J., van Bokhoven, L., Goossens, W., Daniels, R., van der Weijden, T. D., \& Beurskens, S. (2019). Steeds complexere zorg vraagt om teamwerk. Huisarts en Wetenschap, 62(11), 60-63. https://doi.org/10.1007/s12445-019-0305-6

Document status and date:

Published: 01/01/2019

DOI:

10.1007/s12445-019-0305-6

Document Version:

Publisher's PDF, also known as Version of record

\section{Document license:}

Taverne

\section{Please check the document version of this publication:}

- A submitted manuscript is the version of the article upon submission and before peer-review. There can be important differences between the submitted version and the official published version of record.

People interested in the research are advised to contact the author for the final version of the publication, or visit the DOI to the publisher's website.

- The final author version and the galley proof are versions of the publication after peer review.

- The final published version features the final layout of the paper including the volume, issue and page numbers.

Link to publication

\footnotetext{
General rights rights.

- You may freely distribute the URL identifying the publication in the public portal. please follow below link for the End User Agreement:

www.umlib.nl/taverne-license

Take down policy

If you believe that this document breaches copyright please contact us at:

repository@maastrichtuniversity.nl

providing details and we will investigate your claim.
}

Copyright and moral rights for the publications made accessible in the public portal are retained by the authors and/or other copyright owners and it is a condition of accessing publications that users recognise and abide by the legal requirements associated with these

- Users may download and print one copy of any publication from the public portal for the purpose of private study or research.

- You may not further distribute the material or use it for any profit-making activity or commercial gain

If the publication is distributed under the terms of Article $25 \mathrm{fa}$ of the Dutch Copyright Act, indicated by the "Taverne" license above, 


\section{Steeds complexere zorg \\ vraagt om teamwerk}

Jerôme van Dongen, Loes van Bokhoven, Wim Goossens, Ramon Daniëls,

Trudy van der Weijden, Sandra Beurskens

De complexiteit van de zorgvragen in de eerste lijn neemt toe: steeds meer patiënten ervaren zowel somatische als psychische en sociale problemen. Huisartsen hebben een belangrijke rol in het signaleren van deze problemen, maar het vraagt onderlinge afstemming met andere zorg- en welzijnsprofessionals, de patiënt en diens naasten, om tot integrale oplossingen te komen. De onderlinge afstemming in interprofessionele teams is dus belangrijker dan ooit, maar loopt niet als vanzelfsprekend goed. Hoe geef je deze samenwerking vorm?

\section{SAMENWERKEN IS CRUCIAAL}

Op de Woudschotenconferentie van 21 januari 2019 herijkten huisartsen de kernwaarden en kerntaken van het beroep in het licht van maatschappelijke ontwikkelingen. Vanwege de toenemende complexiteit van de zorgvragen stelden huisartsen dat samenwerken cruciaal is voor de uitvoering van het vak. ${ }^{1}$ De huisarts is bij uitstek een teamspeler, zoekt de gezamenlijke aanpak, met de patiënt en met andere betrokken professionals, zowel binnen als buiten de huisartsenzorg. De casus van meneer Derks illustreert hoeveel disciplines betrokken kunnen zijn bij patiënten met complexe zorgvragen. Hij heeft complexe problemen op meerdere (leef)gebieden; denk aan mobiliteit en fysieke gesteldheid, het vermogen om werk of hobby's uit te voeren, de persoonlijke verzorging of het onderhouden van sociale contacten. Dan is een persoonsgerichte benadering gewenst, afgestemd op de verschillende leefgebieden en de voorkeuren van de patiënt. Hierbij wordt gestreefd naar een holistische aanpak, waarbij de persoon centraal staat en niet de ziekte, en die toewerkt naar een gezamenlijk zorgplan. De huisarts heeft een belangrijke rol bij het signaleren van deze problemen, maar hoeft ze niet allemaal zelf aan te pakken. De kernwaarde 'generalistisch' is immers aangescherpt tot 'medisch-generalistisch'. Voor de niet-medische leefgebieden zoekt de huisarts de samenwerking met andere zorg-en welzijnsprofessionals, maar ook met mantelzorgers en andere betrokkenen. Deze interprofessionele samenwerking kunnen we zien als middel om persoonsgerichte zorg te bieden.

In de praktijk blijkt efficiënte en persoonsgerichte interprofessionele teamsamenwerking vaak lastig doordat deze wordt beinvloed door diverse met elkaar samenhangende factoren die

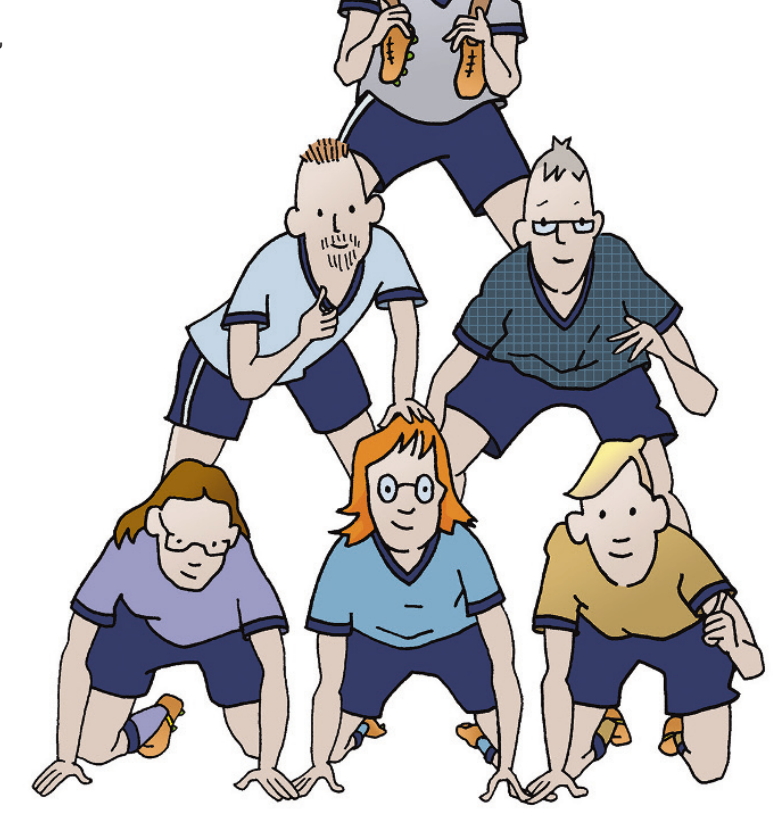

\section{MENEER DERKS}

Meneer Derks is 70 jaar en sinds twee jaar weduwnaar. Hij woont in een eengezinswoning. Hij lijdt al veertien jaar aan diabetes mellitus type 2 en hypertensie. Door zijn zwaarlijvigheid en artrose van de kniegewrichten is hij weinig mobiel. Hij verwaarloost zijn dieet en neemt zijn medicatie onregelmatig. Sinds het overlijden van zijn vrouw isoleert hij zich van zijn omgeving. Verder heeft hij beginnende Alzheimer.

De thuiszorg komt dagelijks om hem te verzorgen en hij gaat twee dagen per week naar een zorgboerderij. De praktijkondersteuner diabetes komt geregeld voor de begeleiding rond de diabetes. Zij houdt ook de algehele conditie en achteruitgang van de cognitie in de gaten. Meneer krijgt fysiotherapie om hem zo lang mogelijk aan het [trap]lopen te houden. Een Wmo-consulent van de gemeente is langs geweest voor aanpassingen in het huis. Meneer komt geregeld met uiteenlopende klachten bij de huisarts. Voor de behandeling van zijn voetklachten is hij onder behandeling bij een podotherapeut. In het ziekenhuis heeft meneer Derks halfjaarlijkse controles bij de internist voor zijn slechte nierfunctie. Tot slot heeft de huisarts, ook op verzoek van de kinderen, voorgesteld om contact te zoeken met maatschappelijk werk, vanwege het aanhoudende verdriet over zijn vrouw.

te maken hebben met structuur en organisatie, interactie en onderliggende processen. ${ }^{2,3}$ Naast vormen van ad hoc-samenwerking, zoals bij verwijzing, hebben veel huisartsen ook te maken met samenwerking met een vast team van professionals. Die teams hebben verschillende namen, zoals multidisciplinair overleg (MDO), hometeam, sociaal team, wijkteam, zorgteam of interprofessioneel teamoverleg. In dit onderzoek zoomen we in op het teamoverleg en gebruiken we de term MDO. 
Met ons onderzoek wilden we inzicht krijgen in de uitdagingen en kritische factoren die een rol spelen bij de interprofessionele samenwerking binnen MDO's in de eerste lijn, rondom het samen opstellen van persoonsgerichte zorgplannen. We hebben in de periode 2012-2017 een promotieonderzoek uitgevoerd, met subsidie van Stichting Innovatie en Alliantie (SIA). ${ }^{4}$

Het onderzoek bevatte drie fases. Fase 1 betrof een probleemanalyse van de huidige werkwijze rondom interprofessioneel samenwerken in het MDO binnen de eerste lijn. De bevindingen uit fase 1 hebben we in fase 2 gebruikt als input voor het ontwikkelen van een programma gericht op het verbeteren van het MDO. Dit hebben we op systematische wijze en in cocreatie met gebruikers gedaan, onder wie professionals en patiënten(vertegenwoordigers). Tot slot hebben we de bruikbaarheid en toepasbaarheid van het programma in fase 3 in een procesevaluatie geëvalueerd.

\section{KRITISCHE FACTOREN [FASE 1]}

Fase 1 van het onderzoek bestond uit een literatuuronderzoek, observaties van MDO's in zestien verschillende huisartsenpraktijken en gezondheidscentra, interviews met 79 deelnemers uit uiteenlopende disciplines, en zes focusgroepinterviews met experts, eerstelijnsprofessionals en patiënten. ${ }^{5-9}$ Dit heeft de volgende verzameling aan kritische succesfactoren opgeleverd.

\section{De kernwaarde persoonsgerichtheid}

Persoonsgerichtheid is altijd een huisartsgeneeskundige kernwaarde geweest en het is inmiddels algemeen bekend dat persoonsgerichtheid de zorg beter afstemt op de wensen van de patiënt. ${ }^{1,10}$ Ons onderzoek liet echter zien dat deelnemers het MDO vaak vanuit een professioneel perspectief benaderen en niet vanuit het perspectief van de persoon. Ze betrekken patiënten er slechts in beperkte mate bij en benoemen de doelen van de patiënt in sommige gevallen zelfs helemaal niet. Patiënten zelf vinden het belangrijk dat ze actief betrokken worden bij het zorgproces en het MDO. ${ }^{9}$ Ze willen vooral een centraal aanspreekpunt hebben en zien graag dat het team een holistische aanpak hanteert. Over de meerwaarde van de aanwezigheid van de patiënt tijdens het teamoverleg of een MDO zijn de meningen verdeeld. Sommige patiënten willen graag zelf aanwezig zijn tijdens een MDO, andere geven aan dat het voldoende is als een teamlid vooraf hun doelen inventariseert en na afloop een terugrapportage geeft. ${ }^{7}$

\section{Een gezamenlijke visie}

Vaak ontbreekt het de interprofessionele teams aan een gezamenlijk gedragen visie en beschouwen ze de samenwerking meer als doel dan als middel. Startpunt in de onderlinge teamsamenwerking is de ontwikkeling van een gezamenlijke visie. ${ }^{11}$ Wanneer je een gezamenlijk doel nastreeft, creëer je naast transparantie ook eigenaarschap en staan de neuzen dezelfde kant op. Een praktisch hulpmiddel om tot een gezamenlijke visie te komen is het Why-how-what-model, ook wel bekend als 'The golden circle.' ${ }^{12}$ Met dit model brengt het team systematisch de gedeelde visie en het bestaansrecht (het waarom), het methodische kader (het hoe) en de belangrijkste kernactiviteiten (het wat) in kaart.

\section{Een passende werkstructuur, procedure en rolverdeling} Ons onderzoek laat zien dat MDO's vaak erg ongestructureerd verlopen. Een agenda ontbreekt, teamleden zijn onvoorbereid, de tijd wordt niet bewaakt, de rolverdeling is onduidelijk, de deelnemers blijven in de mededelingensfeer hangen en de bespreking van casuïstiek mist diepgang. ${ }^{6}$ Een gezamenlijke visie kan echter dienen als basis voor een adequate werkwijze en bijbehorende rolverdeling en procedures. ${ }^{2}$ Welke overlegstructuur hanteren de deelnemers? Wat is de frequentie van overleg? Hoe is de rolverdeling? Hoe worden gemaakte afspraken vastgelegd? Welke aanpak wordt er gebruikt voor de bespreking van casuïstiek? Omdat interprofessionele teams in de eerste lijn geregeld van samenstelling veranderen, kan een overzicht met de belangrijkste spelregels nieuwe leden helpen hun weg te vinden.

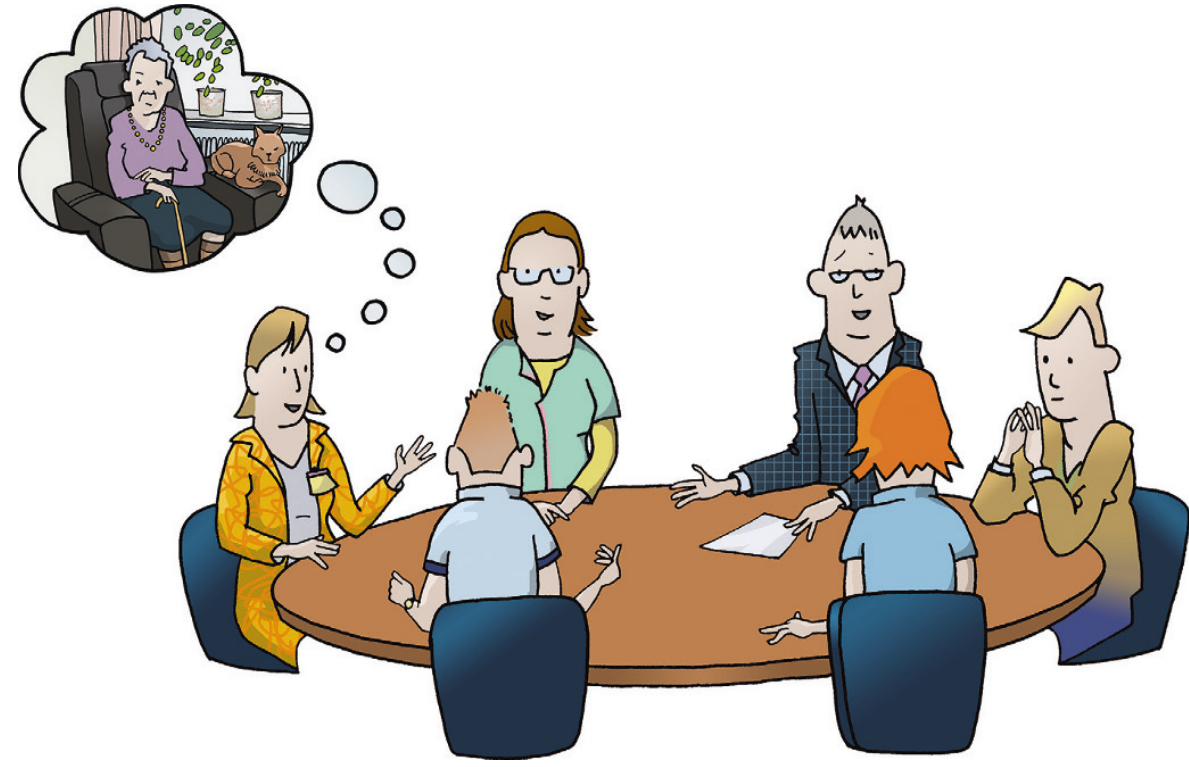

MDO’s verlopen vaak erg ongestructureerd.
Besef van elkaars context, verwachtingen en rol

Vaak lijken teamleden elkaar nauwelijks te kennen. In elk team van professionals van verschillende disciplines en organisaties is het echter van belang dat de leden elkaar zowel persoonlijk als professioneel goed kennen. Het gaat hier om kennis en bewustwording van elkaars achtergronden, verwachtingen en rollen. De deelnemers moeten weten wat de belangen van de andere deelnemers zijn. Door hier met elkaar over te praten kunnen verborgen agenda's worden voorkomen. Teamleden die elkaar goed kennen, zijn beter in staat elkaar gerichte vragen te stellen, te adviseren of te consulteren. 


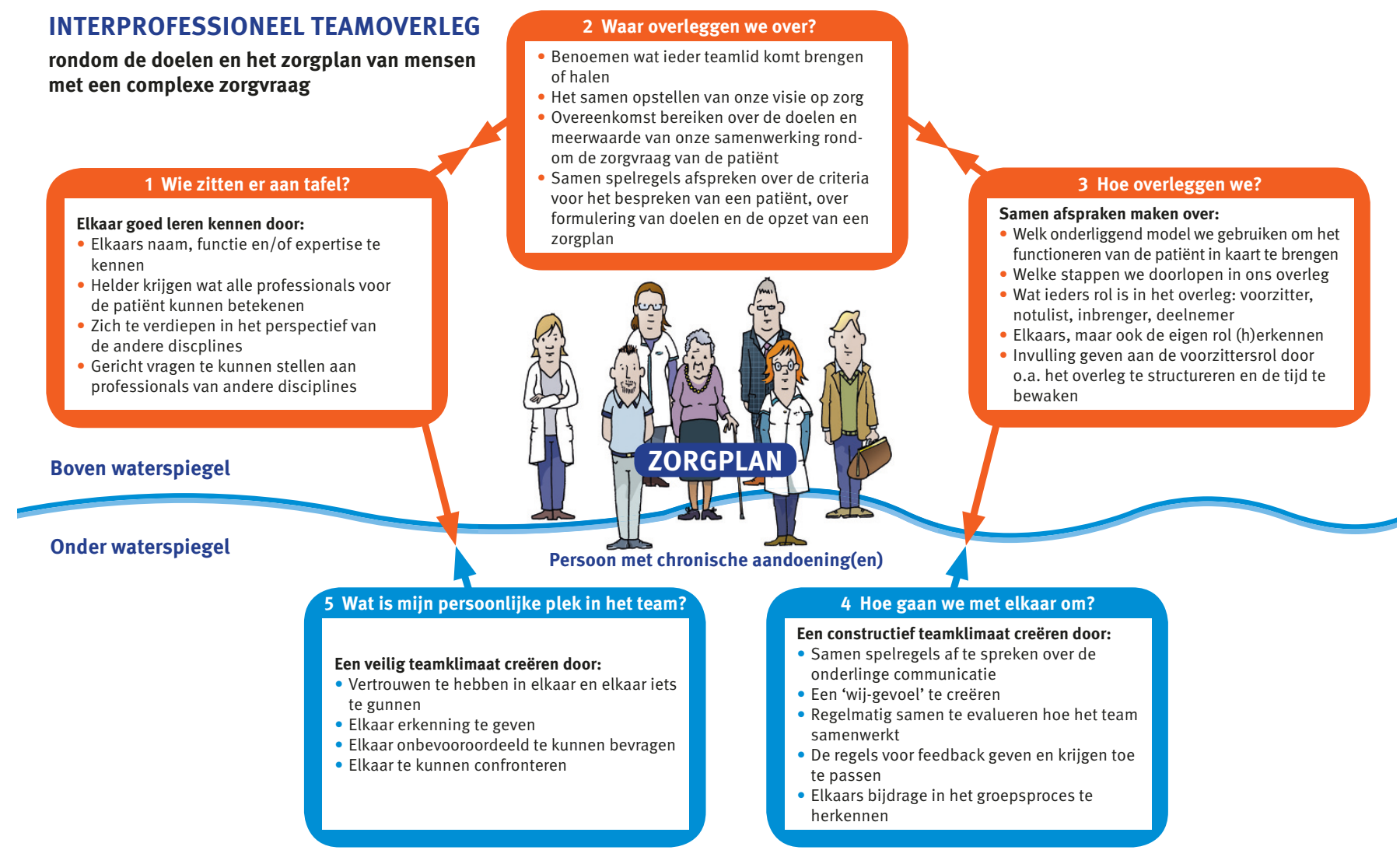

\section{Teamreflectie}

Uit ons onderzoek komt naar voren dat interprofessionele teams in de praktijk weinig tot geen aandacht besteden aan reflectie. Teams zijn vooral bezig met de inhoudelijke bespreking van patiënten (in het bijzonder complexe casuïstiek) en nemen geen tijd om te reflecteren op het (groeps)proces en daarmee ook vaak niet op de effectiviteit van de samenwerking. Idealiter reflecteren ze geregeld op zowel de inhoud en werkwijze, als het groepsproces. Reflectie op de samenwerking kan helpen het teamfunctioneren te verbeteren en hangt positief samen met de teameffectiviteit. ${ }^{13,14}$ Een literatuuronderzoek naar reflectie laat zijn dat een faciliterende context, een veilige sfeer, collegialiteit en tijd samenhangen met een reflectieve praktijk. ${ }^{15}$

\section{Interactie en groepsdynamiek}

Tijdens een interprofessioneel teamoverleg staat vooral het bespreken van de inhoud (casuïstiek) centraal. Expliciete aandacht voor en interventies op de onderlinge interactie en de groepsdynamiek ontbreekt. Onderzoek laat echter zien dat teamsamenwerking gedijt bij aandacht voor groepsinteracties, het teamklimaat en processen van teamontwikkeling. ${ }^{3}$ Wanneer een team goed wil functioneren, is een veilig en constructief klimaat nodig, waarin teamleden elkaar feedback kunnen geven, zich kwetsbaar durven opstellen en hun mening kunnen ventileren. Ook het erkennen van ieders aanwezigheid en bijdrage is van onmiskenbaar belang, net als waardering voor de persoon zelf.

\section{Voorzitter als kartrekker}

Een team dat wil werken vanuit een visie en gemeenschappelijke afspraken, waarbij teamleden elkaar kennen en de patiënt centraal staat, heeft een kartrekker nodig die tot meer in staat is dan alleen het technisch voorzitterschap en bijkomende organisatorische taken, zoals het voorbereiden van het overleg, het versturen van de agenda, zorgen voor een geschikte locatie en het bewaken van de gang van zaken tijdens het overleg. De voorzitter heeft namelijk nog een aantal andere belangrijke taken: het bewaren van een balans tussen het professionele perspectief en de persoonsgerichtheid. Een goede voorzitter is daarbij alert op de invloed van groepsprocessen, bijvoorbeeld wanneer onderlinge irritaties opspelen, en zorgt ervoor dat de kwaliteiten van ieder teamlid tot hun recht komen. Daarnaast initieert en begeleidt de voorzitter periodieke reflectiemomenten om het lerend vermogen van het team te stimuleren. Uit de literatuur is bekend dat een voorzitter die motiveert, inspireert en het team aanzet tot visievorming een positief effect heeft op de mate waarin het team in staat is te reflecteren. ${ }^{16,17}$ De voorzitter moet dus al deze verschillende balletjes in de lucht houden. Doorgaans neemt de huisarts de rol van voorzitter op zich of delegeert deze aan een van de praktijkonder- 
steuners. Ons onderzoek laat zien dat menigeen het voorzitterschap onderschat.

\section{HET VERBETERPROGRAMMA [FASE 2]}

Met de kritische factoren van fase 1 en een aantal voorwaardelijke kaders (ontwikkel een programma met minimale belasting voor het team, dat hands-on en flexibel te hanteren is) als fundament hebben we in fase 2 via actieonderzoek een verbeterprogramma ontwikkeld. ${ }^{18}$ De basis van het programma vormt het Reflectieraamwerk Interprofessioneel Samenwerken in Teams (RIST). Teams kunnen het RIST gebruiken als hulpmiddel bij het verbeteren van het MDO [figuur]. Verder bestaat het programma uit een scholing voor de voorzitters van het team, waarin expliciet aandacht is voor de hierboven beschreven kritische factoren. De scholing bestaat uit een training van twee dagdelen, twee intervisiebijeenkomsten en een coaching on the job-sessie. Aanvullend hebben we een aantal praktische tools ontwikkeld, waaronder een overlegstructuur, een format om spelregels te bespreken en vast te leggen, een formulier dat kan worden gebruikt ter voorbereiding van het teamoverleg, een stappenplan voor het bespreken van casuistiek, een beschrijving van organisatorische rollen en een overzicht met hulpmiddelen voor reflectie.

\section{EVALUATIE VAN HET VERBETERPROGRAMMA [FASE 3]}

Om de ervaren bruikbaarheid, toepasbaarheid en potentiële impact van het programma te evalueren, voerden we in fase 3 een prospectieve procesevaluatie uit in zes interprofessionele eerstelijnspraktijken. ${ }^{19}$ Daarvoor verzamelden we gegevens in de vorm van een voor- en nameting op zowel kwalitatieve (elf interviews en twaalf observaties) als kwantitatieve wijze (vragenlijst). De resultaten van deze evaluatie laten zien dat de deelnemers het programma in zijn geheel positief waarderen. Het meeste resultaat is bereikt op het gebied van de structuur en organisatie van het MDO. De deelnemers ervaren de grootste vooruitgang dan ook dankzij het werken met een agenda, waardoor ze vooraf weten welke patiënt er aan de orde komt en zich daarop gericht kunnen voorbereiden. Ook de concreetheid en doelgerichtheid van het overleg, en een goede tijdsbewaking, waardoor er voor iedere patiënt voldoende tijd is, beoordelen ze positief.

Verder zijn deelnemers zich meer bewust van het belang van persoonsgerichtheid en de invloed van groepsprocessen. Ze geven in de interviews aan dat de nieuwe aanpak teamleden uitdaagt om hun inbreng tijdens een teamoverleg zorgvuldig voor te bereiden door samen met de patiënt diens doelen op voorhand te inventariseren. Daardoor wordt de bespreking van de patiënt tijdens het overleg doelgerichter. Voorzitters zien de trainingsactiviteiten als nuttig en leerzaam, en waarderen vooral de intervisieonderdelen en coaching on the job als effectieve elementen.

\section{WAAR LIGGEN NU NOG DE UITDAGINGEN?}

We zien dat het programma toepasbaar en geschikt is voor verbetering van het functioneren van interprofessionele teams.
Het vergroten van de persoonsgerichtheid in de interprofessionele samenwerking vereist echter meer langdurige aandacht, aanvullende oefening en coaching on the job. De invulling van de voorzittersrol blijkt in de praktijk soms complex. Voorzitters wensen meer coachings- en intervisiemomenten. Wellicht is het nuttig als de voorzitter in het begin door een externe facilitator wordt begeleid. Verder kan het mogelijk helpen om per team een tweede persoon te trainen, als sparringpartner van de voorzitter. ${ }^{20}$

Een van de kritische factoren, een gezamenlijk gedragen visie, lijkt in de praktijk vaak te ontbreken. Een recente review bevestigt het belang hiervan. ${ }^{11}$ Ons onderzoek laat verder zien dat het belangrijk is om doelbewust patiëntgerelateerde informatie met elkaar te delen. Onderzoek van Kim en collega's bevestigt dit - zij spreken van 'spaarzaam' communiceren. ${ }^{21}$

Een andere uitdaging vormt het stimuleren van reflectie. Reflectie komt namelijk niet 'spontaan' op gang, laat staan dat ze een continu karakter heeft. Reflectie vraagt dan ook om een adequate organisatie en interventie, waarbij de voorzitter van het team een essentiële rol speelt. Het programma wordt bij voorkeur aangeboden op de werkvloer en het is wenselijk om zowel vorm als inhoud van het programma aan te passen aan de context en specifieke ontwikkelpunten van het team. Om de ontwikkelpunten van het team te achterhalen en hiermee de reflectie op het functioneren te verbeteren hebben we inmiddels als vervolg op dit onderzoek een hulpmiddel ontwikkeld: de QuickScan Interprofessionele Samenwerking. Deze kan worden ingezet als zelfbeoordelingsinstrument om de kwaliteit van de samenwerking in het team aan de hand van een aantal stellingen en vragen te beoordelen. Het RIST, de diverse tools en de QuickScan zijn vrij beschikbaar.

\section{LITERATUUR}

1. Vos H. Huisarts en complexe zorgvraag. Tijdschr Gezondheidswet 2019;97:20-2.

2. San Martin-Rodriguez L, Beaulieu M-D, D’Amour D, Ferrada-Videla M. The determinants of successful collaboration: a review of theoretical and empirical studies. J Interprof Care 2005;19(sup1):132-47.

3. Xyrichis A, Lowton K. What fosters or prevents interprofessional teamworking in primary and community care? A literature review. Int J Nurs Stud 2008;45:140-53.

De volledige literatuurlijst staat bij dit artikel op www.henw.org.

Van Dongen JJJ, Van Bokhoven MA, Goossens WNM, Daniëls R, Van der Weijden T, Beurskens A. Steeds complexere zorg vraagt om teamwerk. Huisarts Wet 2019;62[11]:60-3. D0I: 10.1007/s12445-019-0305-6. Maastricht University, Vakgroep Huisartsgeneeskunde, Maastricht \& Zuyd Hogeschool, Faculteit Gezondheidszorg, Heerlen: dr. J.J.J. van Dongen, docent-onderzoeker, jerome.vandongen@zuyd.nl; dr. M.A. van Bokhoven, huisarts en universitair hoofddocent; W.N.M. Goossens, expert docent groepsdynamica en teamcoaching; dr. R. Daniëls, lector; prof.dr. T. van der Weijden, hoogleraar; prof.dr. A. Beurskens, lector en hoogleraar.

Mogelijke belangenverstrengeling: niets aangeven. 